\title{
The Impact of BMI Categories on Metabolic Abnormality Development in Chinese Adults Who are Metabolically Healthy: A 7-Year Prospective Study
}

This article was published in the following Dove Press journal:

Diabetes, Metabolic Syndrome and Obesity: Targets and Therapy

\author{
Xiangtong Liu ${ }^{1,2}$ \\ Jingbo Zhang ${ }^{3}$ \\ Jingwei $\mathrm{Wu}^{4}$ \\ Xiaolin $\mathrm{Xu} \mathbb{D}^{5}$ \\ Lixin Tao ${ }^{1,2}$ \\ Yue Sun ${ }^{1,2}$ \\ Shuo Chen ${ }^{3}$ \\ Yumei $\mathrm{Han}^{3}$ \\ Yanxia Luo ${ }^{1,2}$ \\ Xinghua Yang ${ }^{1,2}$ \\ Xiuhua Guo ${ }^{1,2}$ \\ 'School of Public Health, Capital Medical \\ University, Beijing, People's Republic of \\ China; ${ }^{2}$ Beijing Municipal Key Laboratory \\ of Clinical Epidemiology, Beijing, People's \\ Republic of China; ${ }^{3}$ Beijing Physical \\ Examination Center, Beijing, People's \\ Republic of China; ${ }^{4}$ Department of \\ Epidemiology and Biostatistics, College of \\ Public Health, Temple University, PA, \\ USA; ${ }^{5}$ School of Public Health, The \\ University of Queensland, Brisbane, \\ QLD, Australia
}

Correspondence: Xiuhua Guo School of Public Health, Capital Medical University, No. 10 Xitoutiao, You Anmen, Fengtai District, Beijing 100069, People's Republic of China

$\mathrm{Tel} / \mathrm{Fax}+8601083911508$

Email statguo@ccmu.edu.cn
Purpose: To determine what metabolic abnormalities develop frequently among metabolically healthy adults over time according to different baseline body mass index (BMI) categories.

Patients and Methods: A prospective cohort study was performed on 10,805 adults, who were metabolically healthy at the time of the 2008 survey. Participants were divided into four groups: metabolically healthy obese (MHO), metabolically healthy overweight (MHOW), metabolically healthy normal-weight (MHN), and metabolically healthy underweight (MHU). Modified Poisson regression models were used to evaluate the relationship of BMI with the development of metabolic abnormalities. Association rule mining was used to identify the most frequent abnormalities that developed over time.

Results: Compared with the MHN group, the adjusted relative risks of the MHO group were 1.57 (95\% CI: 1.09-2.27) and 2.08 (95\% CI: 1.59-2.73) for developing elevated fasting glucose and elevated blood pressure, respectively, after adjusting for lifestyle behaviours and dietary factors. At the end of follow-up, 33 (19.1\%) MHO subjects and 342 (16.6\%) MHOW subjects had elevated blood pressure as the predominant metabolic syndrome component, whereas $236(9.0 \%)$ MHU subjects had elevated plasma glucose. The results were similar after stratification by sex.

Conclusion: MHO and MHOW subjects developed elevated blood pressure most frequently, and MHU subjects developed elevated blood glucose most commonly, regardless of sex.

Keywords: metabolic diseases, diabetes, hypertension, risk factors

\section{Introduction}

Coronary artery disease is the leading cause of mortality worldwide. ${ }^{1}$ The number of patients suffering from coronary artery disease are 18.2 million and 11 million in the US and China, respectively. ${ }^{2,3}$ Metabolic syndrome (MetS), a constellation of highly heritable risk factors, is an increasingly prevalent predisposing factor for coronary artery disease. ${ }^{4}$ These clinical risk factors associated with MetS include central obesity, high blood pressure, high fasting glucose, high fasting triglyceride and low high-density lipoprotein cholesterol. ${ }^{5}$ The global prevalence of MetS is estimated to be approximately $25 \%$, and over a billion people in the world are now affected by MetS. ${ }^{6}$ The prevalence of MetS was 33.9\% in China, affecting approximately 454 million adults. ${ }^{7}$ Body mass index (BMI) is commonly used to estimate adiposity to evaluate central obesity in MetS patients. A BMI-based MetS score 
operates similarly to a waist circumstance-based score in predicting long-term disease outcomes. ${ }^{5}$

Insulin resistance helps to explain most but not all of the MetS components. Substantial evidence exists regarding the important role of obesity in the development of MetS; therefore, obesity is included as a required prerequisite in the definition of MetS by the International Diabetes Federation. ${ }^{8}$ More importantly, this adds support to the hypothesis that central obesity may trigger the pathogenesis of MetS as the core of MetS and is the antecedent to the development of its other components. ${ }^{8,9}$ Indeed, both cross-sectional and longitudinal studies have implicated obesity as a central feature of this multifaceted condition. ${ }^{9,10}$ A few longitudinal studies have examined the temporal relationships between obesity and other components, implicating that baseline obesity is a strong predictor of the worsening of MetS components. ${ }^{11-13}$

Little is known about the relationship between metabolically healthy obese (MHO) status and the future incidence of individual cardiometabolic abnormalities. The Atherosclerosis Risk in Communities study, a 9-year follow-up of white and African-American adults aged 45-64 years, showed that MHO and metabolically healthy overweight (MHOW) may be related to cardiometabolic abnormality development, and that elevated blood glucose develops most rapidly. ${ }^{14}$

None of these studies, however, have examined a) how the metabolic status changes over time in metabolically healthy individuals according to different BMI categories or b) which metabolic abnormalities dominantly cluster in MHO and MHOW individuals.

We assumed that the clustering of the metabolic abnormalities would develop inconsistently in different BMI categories. It would be expected that one of these abnormalities would appear first in MHOW people, whereas another abnormality would be the first to develop in MHO people. The theoretical model on which this research is based is that if one of the MetS components (eg, central obesity) was itself the underlying cause, it would be expected that this component should initiate the onset of the other components subsequently.

Therefore, the aims of this study were to investigate a) how the profiles of MetS components change over time, b) the effect of BMI on the incidence of MetS and its components after adjusting for confounding factors, and c) which MetS components predominantly appear in MHO, MHOW and MHU participants at the end of a 7-year follow-up.

\section{Materials and Methods}

\section{Study Population}

The Beijing Health Management Cohort (BHMC) study is a large prospective dynamic cohort study that is investigating the progression from a healthy status to the development of metabolic disorders in individuals from urban areas of northeast China. ${ }^{15}$ In the present study, the 2008 survey and the 2015 survey of the BHMC study were used as the starting point and the endpoint of the follow-up, respectively. Participants without MetS at baseline were included, and those with metabolic abnormalities or missing values were excluded. A total of 34,003 individuals were recruited to participate in this study in 2008. Among these individuals, 23,142 subjects who had any individual metabolic abnormality, including prediabetes $(\mathrm{n}=5523)$, prehypertension $(\mathrm{n}=6306)$, hypertriglyceridemia $(\mathrm{n}=3398)$, or lowered highdensity lipoprotein cholesterol $(n=7915)$ at baseline were excluded. After excluding 56 subjects with missing BMI values, the final analysis included 10,805 participants who were followed up from 2008 to 2015.

The study was approved by the Ethics Committee of Capital Medical University (number 2013SY26), and all procedures were performed in accordance with the 1964 Declaration of Helsinki and its later amendments, or comparable ethical standards.

\section{Data Collection}

Physical examination, fasting laboratory measurements, and a health questionnaire interview were performed by trained examiners at baseline and at the end of the 7-year follow-up, after obtaining written informed consent from the participants.

The physical examination, including the measurements of height, weight, waist circumference, hip circumference and blood pressure, was performed by experienced physicians and public health nurses. Both height and body weight were measured with the participant in the upright position to the nearest $0.5 \mathrm{~cm}$ and $0.1 \mathrm{~kg}$, respectively. Waist circumference was measured at the horizontal level between the xiphisternum and umbilicus yielding the minimum measurement. Hip circumference was taken as the horizontal measure around the pelvis at the point of maximal protrusion of the buttocks. Waist and hip circumference were measured twice, and the means were calculated. If duplicate waist or hip measurements differed by $>2 \mathrm{~cm}$, a third measure was taken, and the mean of the closest two was calculated. BMI and waist-to-hip ratio were calculated to measure the overall 
adiposity. After $5 \mathrm{~min}$ of rest in a sitting position, blood pressure measurements were obtained on the right arm of the seated subject using an electronic sphygmomanometer. During the 30 min preceding the measurements, the participants were required to refrain from smoking or ingesting caffeine. Three readings of systolic and diastolic blood pressure were recorded at 1-3 min intervals, and the mean of the last two measurements was used for data analysis.

Fasting laboratory measurements included fasting plasma glucose, triglycerides, and high-density lipoprotein cholesterol. Participants were instructed to fast overnight for at least $12 \mathrm{hrs}$ before blood samples were collected. Fasting plasma glucose, triglycerides, and high-density lipoprotein cholesterol were measured using enzymatic methods on a chemistry analyser (Beckman LX 20, America) in the central laboratory of the hospital. The intra- and inter-assay coefficients of variation for all laboratory tests were under 5\%. All analyses were performed in accordance with the manufacturer's recommendations.

The general health questionnaire covered family history of diabetes and information on lifestyle behaviours (physical activity intensity, sleep duration, alcohol consumption and smoking) and dietary habit factors (breakfast frequency, dietary patterns and eating speed). For the physical activity intensity variable, "high intensity" was defined as swimming, playing ball, or skipping rope; "moderate intensity" was defined as jogging, cycling, or climbing; and "low intensity" was defined as walking, tai chi, or dancing. Sleep duration was recorded according to participants' responses to the question "Over the past three months, what time have you normally gone to bed and woken up?" The speed of eating was self-reported by the response to the question "How fast is your speed of eating?" The responses were chosen from three semi-quantitative categories: "slow", "medium", and "fast". Previous reports have demonstrated good validity and adequate reproducibility of sleep duration and speed of eating, as assessed by self-report, and the measurement and classification of each variable category have been reported elsewhere in detail. ${ }^{16}$ Additionally, some novel confounding factors were also collected, including breakfast frequency and dietary patterns. ${ }^{17,18}$

\section{Diagnosis of Metabolic Syndrome and Metabolic Abnormalities}

MetS was defined according to the 2009 Joint Interim Statement Criteria as the presence of three or more of the following factors: ${ }^{19,20}$
1) Obesity, based on BMI $\geq 30 \mathrm{~kg} \mathrm{~m}^{-2}$;

2) Elevated fasting plasma glucose (FPG) level $\geq$ $5.6 \mathrm{mmol} / \mathrm{L}(100 \mathrm{mg} / \mathrm{dL})$ (drug treatment for elevated glucose was an alternative indicator);

3) Elevated blood pressure: systolic pressure $\geq 130$ and/ or diastolic pressure $\geq 85 \mathrm{~mm} \mathrm{Hg}$ (anti-hypertensive drug treatment in a patient with a history of hypertension was an alternative indicator);

4) Triglyceride level $\geq 1.7 \mathrm{mmol} / \mathrm{L}(150 \mathrm{mg} / \mathrm{dL})$ or current medication for dyslipidaemia;

5) Reduced high-density lipoprotein cholesterol (HDLC) level $<1.0 \mathrm{mmol} / \mathrm{L}(40 \mathrm{mg} / \mathrm{dL})$ in men and $<1.3 \mathrm{mmol} / \mathrm{L}(50 \mathrm{mg} / \mathrm{dL})$ in women (drug treatment for reduced HDLC level was an alternative indicator).

As there is no standard definition for MHO, we considered four metabolic abnormalities for our analyses: (1) prediabetes was defined as a fasting serum glucose $\geq$ $5.55 \mathrm{mmol}^{-1}$ or current use of blood glucose lowering agents; (2) prehypertension was defined as a blood pressure $\geq 130 / 85 \mathrm{mmHg}$ or current use of blood pressurelowering agents; (3) hypertriglyceridemia was defined as triglycerides $\geq 1.69 \mathrm{mmol}^{-1}$; and (4) low HDLC was defined as HDLC $<1.03$ mmol. $^{19}$

\section{Statistical Analysis}

Data are presented as the mean \pm standard deviation for continuous variables and count (percentages) for categorical variables. Baseline characteristics of the participants were compared by either independent two-sample $\mathrm{t}$ tests or Chisquare tests between MetS statuses (with MetS vs without MetS) at the end of the 7-year follow-up. Mean change values of fasting plasma glucose, triglycerides, systolic blood pressure, diastolic blood pressure and high-density lipoprotein cholesterol from baseline to the 7-year followup among four BMI categories were assessed by analysis of variance (ANOVA) tests. The incidence trends among BMI categories was assessed by the Cochran-Armitage trend z-test. BMI was categorized based on the WHO criteria: (i) underweight $=\mathrm{BMI}<18.5 \mathrm{~kg} \mathrm{~m}^{-2}$, normal weight $=$ BMI of $18.5-24.9 \mathrm{~kg} \mathrm{~m}^{-2}$, overweight $=$ BMI of $25.0-29.9 \mathrm{~kg} \mathrm{~m}^{-2}$, and obese $=$ BMI $\geq 30.0 \mathrm{~kg} \mathrm{~m}^{-2} \cdot{ }^{21}$ We categorized the patients as follows: metabolically healthy underweight (MHU), metabolically healthy normal-weight (MHN), metabolically healthy overweight (MHOW) and metabolically healthy obese (MHO). 
Modified Poisson regression analyses were performed to examine the association between the development of each metabolic abnormality and BMI categories, and the adjusted relative risk (RR) and 95\% confidence interval (CI) were presented. The modified Poisson regression analyses combine a log Poisson regression model with robust error variance estimation, which is reliable for estimating relative risks from prospective data. ${ }^{22}$ All potential confounding variables in the regression analyses were assessed at baseline in 2008. We present the results of three different models. The null model was adjusted for age, age squared, age cubed and sex. Then, based on the null model, nine risk factors were additionally adjusted separately, including parental history of diabetes, waist-hip ratio, breakfast frequency, dietary patterns, eating speed, physical activity intensity, sleep duration, alcohol consumption, and smoking. Last, the full model, which was based on the null model, was additionally adjusted for all nine risk factors simultaneously. The extent to which the nine risk factors attenuated the relationship between BMI categories and metabolic abnormalities incidence was investigated by comparing the coefficients before and after adjusting for different risk factors $\left(\Delta \beta\right.$ percent $=100 *\left(\beta_{\text {Null model }}-\right.$ $\left.\left.\beta_{\text {Null model +risk factor }}\right) / \beta_{\text {Null model }}\right){ }^{23}$

Association rule mining (ARM) is a data mining method designed to identify groups of variables with respect to a specific target variable. ARM has been applied in assessing the cooccurrence of lifestyle risk behaviours and in predicting acute myocardial infarction. ${ }^{24,25}$ The strength of this analytical method is that ARM measures the support, confidence, and lift of the rule, as explained below. For a rule $(A \Rightarrow B)$, the support rate is the probability that the two components occur together, and the confidence rate is the conditional probability of the existence of component $\mathrm{B}$ given that a person has component $\mathrm{A}$. Then, the lift value is the confidence divided by the support, which is interpreted as a general measure of the association between the components of MetS. Lift values greater than 1 indicate a positive correlation, values equal to 1 indicate zero correlation, and values less than 1 indicate a negative correlation.

The ARM method was used to analyse the changes in each MetS component or combinations stratified by sex and BMI level during the 7-year period of this study. The data are expressed as transitions of statuses that changed from baseline to the end of 7-year follow-up, with "healthy" defined as being free of any MetS components. Based on the top ten rules (transitions of statuses), we established a confidence threshold of $5 \%$ for men and
$1.2 \%$ for women as there were fewer rules for women than men. We set the threshold of lift as "over 1". The lift threshold over 1 meant that we accepted the positive association.

Data were analysed using SAS software version 9.4 (SAS Institute, Cary, NC, USA). Association rule mining was performed using the "arulesViz" package of R software. A two-sided $\alpha$ of 0.05 was considered statistically significant. Bonferroni adjustment of critical $P$-values was adopted when performing multiple comparisons.

\section{Results \\ Characteristics of Participants}

A total of 10,805 eligible participants were included in the analysis with a median age of 42 years. A total of 5392 $(49.9 \%)$ males were included, with a median age of 41 years old $(43.0 \pm 14.5)$, while $5413(50.1 \%)$ females were included, with a median age of 39 years old $(40.6 \pm 12.5)$. The average follow-up interval was $6.8 \pm 0.4$ years. At baseline, $1.6 \%$ of the subjects were MHO, $19.1 \%$ were MHOW, $55.1 \%$ were MHN, and $24.2 \%$ were MHU. The detailed baseline characteristics of the study population are presented according to the MetS status at follow-up (Table 1). The MetS group tended to be older and had higher body mass index, fasting plasma glucose, triglyceride, systolic blood pressure, diastolic blood pressure, and waist-hip ratio values but lower high-density lipoprotein cholesterol and sleep duration values.

\section{Profiles of Changes in Individual MetS Components}

Profiles of the individual MetS components of all subjects and of males and females stratified by different BMI categories were analysed (Table 2). Seven-year changes in fasting plasma glucose were not the same in all four BMI categories ( $\mathrm{F}=20.69, P<0.001)$, which was also consistently shown in the subgroup analysis stratified by $\operatorname{sex}\left(\mathrm{F}_{\mathrm{men}}=4.83\right.$, $\left.P_{\text {men }}=0.002 ; \mathrm{F}_{\text {women }}=15.50, P_{\text {women }}<0.001\right)$. Similar results were found for seven-year changes in systolic blood pressure and diastolic blood pressure. Seven-year changes in triglyceride in males were not the same in the four BMI categories $(\mathrm{F}=3.27, P=0.020)$.

\section{The Incidence of Metabolic Abnormalities}

At the end of the 7-year follow-up, 1310, 1695, and 1203 participants developed elevated fasting glucose, blood pressure, and triglycerides, respectively, and 2582 participants 
Table I Distribution of Baseline (2008) Characteristics of Participants $(n=10,805)$ Grouped by MetS Status at the End of 7-Year Follow-Up

\begin{tabular}{|c|c|c|c|}
\hline Variables & $\begin{array}{l}\text { No MetS } \\
(n=10,478)\end{array}$ & $\begin{array}{l}\text { MetS } \\
(n=327)\end{array}$ & $P$ value \\
\hline Men, n (\%) & $5163(49.3)$ & $228(69.7)$ & $<0.001^{a}$ \\
\hline Age (years), mean $\pm S D$ & $41.73 \pm 13.53$ & $43.50 \pm 13.78$ & $0.020^{b}$ \\
\hline $\mathrm{BMI}\left(\mathrm{kg} / \mathrm{m}^{2}\right)$, mean $\pm \mathrm{SD}$ & $22.95 \pm 3.04$ & $26.62 \pm 3.43$ & $<0.001^{b}$ \\
\hline $\mathrm{FPG}(\mathrm{mmol} / \mathrm{L})$, mean $\pm \mathrm{SD}$ & $4.93 \pm 0.38$ & $5.10 \pm 0.35$ & $<0.001^{b}$ \\
\hline TG $(\mathrm{mmol} / \mathrm{L})$, mean $\pm \mathrm{SD}$ & $0.90 \pm 0.34$ & $1.18 \pm 0.30$ & $<0.001^{b}$ \\
\hline $\mathrm{SBP}(\mathrm{mmHg})$, mean $\pm \mathrm{SD}$ & $108.7 \pm 9.87$ & $114.0 \pm 8.58$ & $<0.001^{b}$ \\
\hline $\mathrm{DBP}(\mathrm{mmHg})$, mean $\pm \mathrm{SD}$ & $71.96 \pm 6.97$ & $75.34 \pm 6.16$ & $<0.001^{b}$ \\
\hline $\mathrm{HDLC}(\mathrm{mmol} / \mathrm{L})$, mean $\pm \mathrm{SD}$ & $1.50 \pm 0.31$ & $1.30 \pm 0.22$ & $<0.001^{b}$ \\
\hline $\begin{array}{l}\text { Parental history of diabetes, } n \\
\text { (\%) }\end{array}$ & $2043(19.5)$ & I 47 (44.9) & $<0.001^{a}$ \\
\hline Waist-hip ratio, mean \pm SD & $0.78 \pm 0.07$ & $0.83 \pm 0.08$ & $<0.001^{b}$ \\
\hline \multicolumn{4}{|l|}{ Breakfast frequency, n (\%) } \\
\hline Never & $1297(12.4)$ & $47(14.4)$ & $0.230^{\mathrm{a}}$ \\
\hline$\leq 2$ times/week & $1052(10.0)$ & $23(7.0)$ & \\
\hline 3-6 times/week & $1350(12.9)$ & $39(11.9)$ & \\
\hline$\geq 7$ times/week & $6779(64.7)$ & $218(66.7)$ & \\
\hline \multicolumn{4}{|l|}{ Dietary patterns, n (\%) } \\
\hline Balanced & $8194(78.2)$ & $250(76.4)$ & 0.246 \\
\hline More meat & $2148(20.5)$ & $69(21.2)$ & \\
\hline More vegetarian & $136(1.3)$ & $8(2.4)$ & \\
\hline \multicolumn{4}{|l|}{ Eating speed, n (\%) } \\
\hline Slow & $1012(9.7)$ & $17(5.2)$ & $<0.001^{a}$ \\
\hline Medium & $4334(41.3)$ & $118(36.1)$ & \\
\hline Fast & $5132(49.0)$ & $192(58.7)$ & \\
\hline \multicolumn{4}{|l|}{ Physical activity intensity, n (\%) } \\
\hline Large & $|35|(12.9)$ & $28(8.6)$ & $0.044^{a}$ \\
\hline Medium & $2985(28.5)$ & $104(31.8)$ & \\
\hline Mild & $2794(26.7)$ & $99(30.3)$ & \\
\hline None & $3348(31.9)$ & $96(29.3)$ & \\
\hline Sleep duration, mean \pm SD & $7.5 \pm 1.2$ & $7.1 \pm 1.2$ & $<0.001^{b}$ \\
\hline \multicolumn{4}{|l|}{ Alcohol consumption, n (\%) } \\
\hline Never & $3478(33.2)$ & $75(22.9)$ & $<0.001^{a}$ \\
\hline$<1.5 \mathrm{~kg} /$ month & $5479(52.3)$ & $186(56.9)$ & \\
\hline $1.5-3 \mathrm{~kg} / \mathrm{month}$ & $1093(10.4)$ & $40(12.2)$ & \\
\hline$>3 \mathrm{~kg} /$ month & $428(4.1)$ & $26(8.0)$ & \\
\hline \multicolumn{4}{|l|}{ Smoking, n (\%) } \\
\hline Never smoker & 4545 (43.4) & $95(29.1)$ & $<0.001^{a}$ \\
\hline I-5 cigarettes/day & $4467(42.6)$ & $162(49.5)$ & \\
\hline $6-20$ cigarettes/day & $1165(11.1)$ & $53(16.2)$ & \\
\hline$>21$ cigarettes/day & $301(2.9)$ & $17(5.2)$ & \\
\hline
\end{tabular}

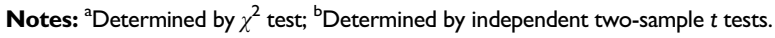
Abbreviations: MetS, metabolic syndrome; SD, standard deviation; BMI, body mass index; FPG, fasting plasma glucose; TG, triglyceride; SBP, systolic blood pressure; DBP, diastolic blood pressure; HDLC, high-density lipoprotein cholesterol.

had a reduction in high-density lipoprotein cholesterol. The incidence of metabolic abnormalities at follow-up was analysed according to BMI categories at baseline (Figure 1). The incidence of MetS in all participants and in males and females was $3.03 \%$ (95\% CI: $2.70-3.34 \%), 4.23 \%$ (95\% CI: $3.68-4.75 \%$ ) and $1.83 \%$ (95\% CI: $1.47-2.18 \%)$, respectively. The incidence in males was statistically significantly higher than that in females $\left(\chi^{2}=53.30, P<0.001\right)$. The incidence of MetS in the MHN, MHU, MHOW and MHO groups was $1.46 \%$ (95\% CI: $1.16-1.77 \%), 2.76 \%$ (95\% CI: 2.16-3.43\%), 6.25\% (95\% CI: $5.20-7.29 \%$ ), and $22.54 \%$ (95\% CI: $16.32-28.77 \%$ ), respectively $(\mathrm{Z}=-6.36, P$ for trend $<0.001)$.

\section{The Association Between BMI Categories and Incident Metabolic Abnormalities}

We examined the association between the development of each metabolic abnormality and BMI categories, and the adjusted RR and 95\% CIs are presented in Table 3. After adjusting for potential confounding factors, individuals with MHO and MHOW had a 1.23 -fold (95\% CI: $1.15-$ 1.32 ), and 1.05 -fold (95\% CI: $1.03-1.08)$ greater risk for developing MetS than individuals in the MHN group. Individuals with MHO had a 1.57 -fold $(95 \%$ CI: 1.09 2.27) greater risk for elevated fasting glucose, a 2.08 -fold (95\% CI: 1.59-2.73) greater risk for elevated blood pressure, a 1.92-fold (95\% CI: 1.08-3.41) greater risk for elevated triglycerides, and a 1.60 -fold $(95 \%$ CI: $1.26-$ 2.03) greater risk for low HDLC. Individuals with MHOW had a 1.46-fold (95\% CI: $1.20-1.78)$ greater risk for elevated fasting glucose, a 1.68 -fold $(95 \%$ CI: $1.43-$ 1.98) greater risk for elevated blood pressure, a 2.21 -fold (95\% CI: 1.67-2.92) greater risk for elevated triglycerides, and a 1.38 -fold (95\% CI: $1.21-1.57)$ greater risk for low HDLC.

The extent to which the nine risk factors attenuated the relationship between BMI categories and metabolic abnormality incidence was investigated by comparing the coefficients before and after adjusting for different risk factors $(\Delta \beta)$ (Table 3$)$. The RR of metabolically healthy obese individuals for the development of elevated fasting glucose was 1.85 (95\% CI 1.27-2.70). There was modest attenuation of inequalities when adding risk factors to the models, with the waist-hip ratio (38\%) making the greatest contribution to the inequalities. Accounting for differences in all nine risk factors resulted in a $27 \%$ attenuation of coefficients in the model, indicating that the majority of elevated fasting glucose development remained unexplained by these nine risk factors in obese individuals. 
Table 2 Profiles of MetS Components of Subjects, Stratified by Different BMI Categories at Baseline

\begin{tabular}{|c|c|c|c|c|c|c|c|c|}
\hline & $\begin{array}{l}\text { Variable } \\
\text { (Mean } \pm \text { SD) }\end{array}$ & & MHU & MHN & MHOW & МHO & $\boldsymbol{F}$ & $P$ value* \\
\hline \multirow[t]{16}{*}{ Total } & $\mathrm{n}$ & & 2612 & 5955 & 2065 & 173 & & \\
\hline & \multirow[t]{3}{*}{ FPG (mmol/L) } & Baseline & $5.0 \pm 0.4$ & $4.9 \pm 0.4$ & $5.0 \pm 0.4$ & $5.0 \pm 0.4$ & & \\
\hline & & Follow-up & $5.2 \pm 0.4$ & $5.2 \pm 0.5$ & $5.3 \pm 0.6$ & $5.3 \pm 0.6$ & & \\
\hline & & $\Delta$ Follow-up-Baseline & $0.2 \pm 0.5$ & $0.2 \pm 0.5$ & $0.3 \pm 0.7$ & $0.4 \pm 0.6$ & 20.69 & $<0.001$ \\
\hline & \multirow[t]{3}{*}{ TG (mmol/L) } & Baseline & $0.8 \pm 0.3$ & $0.9 \pm 0.3$ & $1.1 \pm 0.3$ & $1.3 \pm 0.3$ & & \\
\hline & & Follow-up & $1.0 \pm 0.6$ & $\mathrm{I} . \mathrm{I} \pm 0.7$ & $\mathrm{I} .4 \pm \mathrm{I} . \mathrm{I}$ & $1.4 \pm 0.6$ & & \\
\hline & & $\Delta$ Follow-up-Baseline & $0.2 \pm 0.5$ & $0.2 \pm 0.6$ & $0.3 \pm 1.0$ & $0.1 \pm 0.6$ & 9.23 & $<0.001$ \\
\hline & \multirow[t]{3}{*}{$\mathrm{SBP}(\mathrm{mmHg})$} & Baseline & $105.0 \pm 10.2$ & $108.6 \pm 9.7$ & $1 \mid 3.1 \pm 8.1$ & $115.5 \pm 8.4$ & & \\
\hline & & Follow-up & $110.8 \pm 14.2$ & $113.8 \pm 13.2$ & $122.2 \pm 13.8$ & $128.6 \pm 12.9$ & & \\
\hline & & $\Delta$ Follow-up-Baseline & $4.7 \pm 12.6$ & $5.2 \pm 12.8$ & $9.1 \pm 13.8$ & $12.6 \pm 13.3$ & 61.14 & $<0.001$ \\
\hline & \multirow[t]{3}{*}{$\mathrm{DBP}(\mathrm{mmH})$} & Baseline & $69.6 \pm 7.3$ & $71.8 \pm 6.8$ & $75.0 \pm 5.9$ & $77.4 \pm 4.7$ & & \\
\hline & & Follow-up & $72.2 \pm 9.4$ & $71.3 \pm 9.3$ & $76.0 \pm 9.5$ & $79.5 \pm 9.2$ & & \\
\hline & & $\Delta$ Follow-up-Baseline & $1.9 \pm 8.9$ & $-0.4 \pm 9.0$ & $1.0 \pm 9.6$ & $2.1 \pm 9.2$ & 34.13 & $<0.001$ \\
\hline & \multirow[t]{3}{*}{ HDLC (mmol/L) } & Baseline & $1.6 \pm 0.3$ & $1.5 \pm 0.3$ & $1.3 \pm 0.2$ & $1.3 \pm 0.2$ & & \\
\hline & & Follow-up & $1.5 \pm 0.3$ & $1.4 \pm 0.3$ & $1.2 \pm 0.3$ & $1.2 \pm 0.3$ & & \\
\hline & & $\Delta$ Follow-up-Baseline & $-0.1 \pm 0.3$ & $-0.1 \pm 0.3$ & $-0.1 \pm 0.2$ & $-0.1 \pm 0.2$ & 4.24 & 0.005 \\
\hline \multirow[t]{16}{*}{ Men } & $\mathrm{n}$ & & 553 & 3123 & 1575 & $14 \mid$ & & \\
\hline & \multirow[t]{3}{*}{ FPG (mmol/L) } & Baseline & $4.9 \pm 0.4$ & $5.0 \pm 0.4$ & $5.0 \pm 0.4$ & $5.0 \pm 0.4$ & & \\
\hline & & Follow-up & $5.3 \pm 0.5$ & $5.2 \pm 0.5$ & $5.3 \pm 0.6$ & $5.3 \pm 0.6$ & & \\
\hline & & $\Delta$ Follow-up-Baseline & $0.4 \pm 0.5$ & $0.3 \pm 0.5$ & $0.3 \pm 0.7$ & $0.4 \pm 0.7$ & 4.83 & 0.002 \\
\hline & \multirow[t]{3}{*}{ TG (mmol/L) } & Baseline & $1.0 \pm 0.3$ & $1.0 \pm 0.3$ & $1.1 \pm 0.3$ & $1.3 \pm 0.2$ & & \\
\hline & & Follow-up & $\mathrm{I} .3 \pm 0.8$ & $1.2 \pm 0.7$ & $1.4 \pm 1.2$ & $1.4 \pm 0.6$ & & \\
\hline & & $\Delta$ Follow-up-Baseline & $0.3 \pm 0.7$ & $0.3 \pm 0.7$ & $0.3 \pm 1.1$ & $0.1 \pm 0.6$ & 3.27 & 0.020 \\
\hline & \multirow[t]{3}{*}{$\mathrm{SBP}(\mathrm{mmH})$} & Baseline & $109.2 \pm 9.9$ & $111.7 \pm 8.4$ & $113.8 \pm 7.7$ & $115.4 \pm 8.3$ & & \\
\hline & & Follow-up & $118.4 \pm 15.9$ & $117.4 \pm 12.3$ & $123.0 \pm 13.2$ & $129.2 \pm 13.4$ & & \\
\hline & & $\Delta$ Follow-up-Baseline & $6.2 \pm 12.9$ & $5.8 \pm 12.6$ & $9.2 \pm 13.3$ & $13.5 \pm 13.9$ & 33.65 & $<0.001$ \\
\hline & \multirow[t]{3}{*}{$\mathrm{DBP}(\mathrm{mmHg})$} & Baseline & $72.3 \pm 7.2$ & $73.6 \pm 6.3$ & $75.5 \pm 5.7$ & $77.4 \pm 4.7$ & & \\
\hline & & Follow-up & $75.7 \pm 10.9$ & $73.7 \pm 9.1$ & $76.9 \pm 9.4$ & $80.3 \pm 9.2$ & & \\
\hline & & $\Delta$ Follow-up-Baseline & $0.1 \pm 8.5$ & $0.1 \pm 9.1$ & $1.4 \pm 9.4$ & $2.9 \pm 9.3$ & 9.13 & $<0.001$ \\
\hline & \multirow[t]{3}{*}{ HDLC (mmol/L) } & Baseline & $1.4 \pm 0.3$ & $1.4 \pm 0.3$ & $1.3 \pm 0.2$ & $1.2 \pm 0.2$ & & \\
\hline & & Follow-up & $1.3 \pm 0.3$ & $1.3 \pm 0.3$ & $1.2 \pm 0.2$ & $1.1 \pm 0.2$ & & \\
\hline & & $\Delta$ Follow-up-Baseline & $-0.1 \pm 0.3$ & $-0.1 \pm 0.2$ & $-0.1 \pm 0.2$ & $-0.1 \pm 0.2$ & 0.62 & 0.605 \\
\hline
\end{tabular}

(Continued) 
Table 2 (Continued).

\begin{tabular}{|c|c|c|c|c|c|c|c|c|}
\hline & $\begin{array}{l}\text { Variable } \\
(\text { Mean } \pm \text { SD) }\end{array}$ & & MHU & MHN & MHOW & МНО & $\boldsymbol{F}$ & $P$ value* \\
\hline \multirow[t]{16}{*}{ Women } & $\mathrm{n}$ & & 2059 & 2832 & 490 & 32 & & \\
\hline & \multirow[t]{3}{*}{ FPG (mmol/L) } & Baseline & $5.0 \pm 0.3$ & $4.9 \pm 0.4$ & $4.9 \pm 0.4$ & $5.0 \pm 0.4$ & & \\
\hline & & Follow-up & $5.1 \pm 0.4$ & $5.1 \pm 0.4$ & $5.3 \pm 0.7$ & $5.4 \pm 0.5$ & & \\
\hline & & $\Delta$ Follow-up-Baseline & $0.2 \pm 0.4$ & $0.2 \pm 0.4$ & $0.3 \pm 0.8$ & $0.5 \pm 0.5$ & 15.50 & $<0.001$ \\
\hline & \multirow[t]{3}{*}{ TG (mmol/L) } & Baseline & $0.8 \pm 0.3$ & $0.8 \pm 0.3$ & $1.0 \pm 0.3$ & $1.2 \pm 0.3$ & & \\
\hline & & Follow-up & $1.0 \pm 0.5$ & $0.9 \pm 0.5$ & $1.2 \pm 0.7$ & $1.2 \pm 0.3$ & & \\
\hline & & $\Delta$ Follow-up-Baseline & $0.2 \pm 0.4$ & $0.2 \pm 0.5$ & $0.2 \pm 0.6$ & $0.0 \pm 0.4$ & 2.00 & 0.112 \\
\hline & \multirow[t]{3}{*}{$\mathrm{SBP}(\mathrm{mmHg})$} & Baseline & $104.4 \pm 10.1$ & $105.2 \pm 9.9$ & $111.1 \pm 9.0$ & $115.7 \pm 9.0$ & & \\
\hline & & Follow-up & $109.0 \pm 13.1$ & $109.7 \pm 12.9$ & $119.9 \pm 15.4$ & $125.1 \pm 9.2$ & & \\
\hline & & $\Delta$ Follow-up-Baseline & $4.4 \pm 12.5$ & $4.6 \pm 13.0$ & $8.6 \pm 15.5$ & $8.2 \pm 7.9$ & 13.73 & $<0.001$ \\
\hline & \multirow[t]{3}{*}{$\mathrm{DBP}(\mathrm{mmHg})$} & Baseline & $69.2 \pm 7.2$ & $69.7 \pm 6.8$ & $73.5 \pm 6.2$ & $77.3 \pm 4.9$ & & \\
\hline & & Follow-up & $71.4 \pm 8.8$ & $68.8 \pm 8.9$ & $73.1 \pm 9.6$ & $75.4 \pm 8.2$ & & \\
\hline & & $\Delta$ Follow-up-Baseline & $2.1 \pm 9.0$ & $-0.9 \pm 8.9$ & $-0.3 \pm 10.0$ & $-2.0 \pm 7.0$ & 39.07 & $<0.001$ \\
\hline & \multirow[t]{3}{*}{$\mathrm{HDLC}(\mathrm{mmol} / \mathrm{L})$} & Baseline & $1.7 \pm 0.3$ & $1.7 \pm 0.3$ & $1.6 \pm 0.2$ & $1.5 \pm 0.1$ & & \\
\hline & & Follow-up & $1.5 \pm 0.3$ & $1.5 \pm 0.3$ & $1.4 \pm 0.3$ & $1.4 \pm 0.3$ & & \\
\hline & & $\Delta$ Follow-up-Baseline & $-0.1 \pm 0.3$ & $-0.1 \pm 0.3$ & $-0.1 \pm 0.3$ & $-0.1 \pm 0.2$ & 0.45 & 0.715 \\
\hline
\end{tabular}

Note: $* P$-value was based on ANOVA test.

Abbreviations: MetS, metabolic syndrome; BMI, body mass index; SD, standard deviation; FPG, fasting plasma glucose; TG, triglyceride; SBP, systolic blood pressure; DBP, diastolic blood pressure; HDLC, high-density lipoprotein cholesterol.

Similarly, the RR of metabolically healthy obese individuals for the development of elevated blood pressure was 2.51 (95\% CI 1.96-3.22). There was modest attenuation of inequalities when adding risk factors to the models, with physical activity (17\%) and waist-hip ratio (17\%), followed by sleep $(16 \%)$, contributing most to the inequalities. Accounting for differences in all nine risk factors resulted in a total of $20 \%$ attenuation of coefficients in the model, indicating that the minority of inequalities in the development of elevated blood pressure can be explained by these nine risk factors.

\section{Common Changes in Metabolic Status}

The support rate of the most common status change (defined as the percentage of participants changing from the initial status to another status via all possible transitions), confidence rate (defined as the conditional probability of a specific new-onset component given the presence of a component) and lift value (greater than 1 indicates a positive correlation) were examined (Table 4).
For visual simplicity, the ten most commonly observed transitions ranked by confidence rate for all subjects and for men and women are shown in Figure 2, Figures 3 and 4, respectively. For example, 553 men were initially MHU at baseline, and $324(58.6 \%)$ of these men maintained an absence of any components, while 65 (11.8\%) developed elevated plasma glucose by the end of the observation period.

Thirty-three out of 173 (19.1\%) subjects who were MHO and 342 out of 2065 (16.6\%) subjects who were MHOW developed elevated blood pressure as the primary component, whereas 236 out of $2612(9.0 \%)$ MHU subjects developed elevated plasma glucose as the most common component of MetS. As expected, the most common transition was from healthy to healthy in the MHU and MHN groups (1898 (72.7\%) and 4313 (72.4\%), respectively), whereas 39 out of 173 (22.5\%) MHO subjects remained unchanged.

Stratified by sex, 29 (20.6\%) males who were MHO and $261(16.6 \%)$ males and $81(16.5 \%)$ females who were MHOW developed elevated blood pressure as the most 


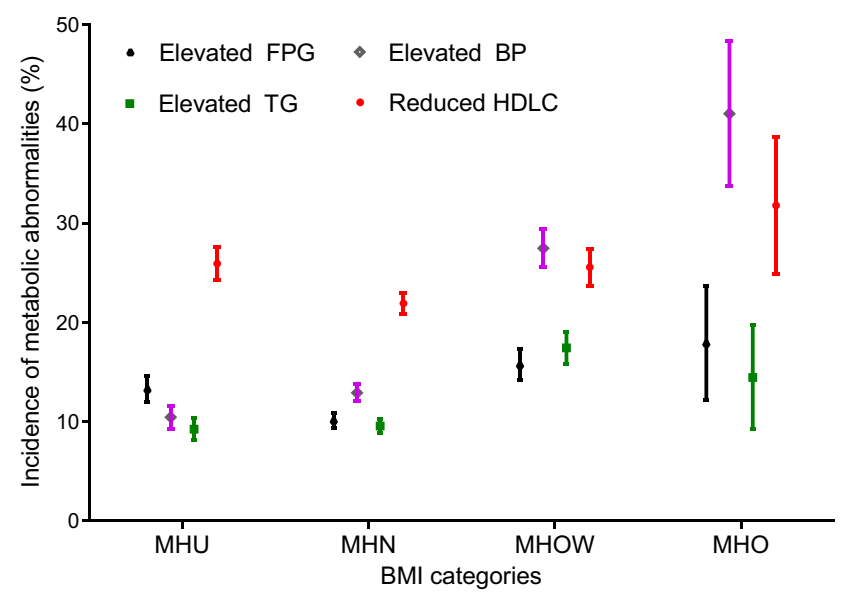

Figure I The accumulated incidence of metabolic abnormalities stratified by BMI categories at baseline.

frequent component. Sixty-five (11.8\%) males and 100 (4.9\%) females who were MHU developed elevated fasting glucose. Among the 141 males with MHO, 31 (22.0\%) remained unchanged, and 29 (20.6\%) had elevated blood pressure as the primary additional component. Males with MHOW were more susceptible to developing high blood pressure $(261 / 1575,16.6 \%)$ and high triglyceride (153/ $1575,9.7 \%$ ), whereas males who were MHU were more likely to develop elevated plasma glucose $(65 / 553$, $11.8 \%$ ). Females who were MHOW were more likely to develop high blood pressure $(81 / 490,16.5 \%)$ and high triglycerides $(38 / 490,7.8 \%)$, and in the MHU group, elevated plasma glucose $(100 / 2059,4.9 \%)$ and high triglycerides $(153 / 2059,9.7 \%)$ were more likely to occur separately.

\section{Discussion}

The current study linked the patterns of longitudinal changes in MetS components to BMI categories at baseline in metabolically healthy Chinese urban adults after adjusting for other well-known metabolic risk factors. MHO and MHOW were significantly associated with a greater risk of developing MetS and individual metabolic abnormalities. Furthermore, subjects who were MHO and MHOW developed elevated blood pressure most frequently, and MHU subjects developed elevated blood glucose most commonly regardless of sex.

\section{Comparison with Other Studies and Implications}

In our study, MHO or MHOW individuals had a higher relative risk of developing individual components of MetS than individuals in the MHN group after adjusting for lifestyles factors, dietary habits and sleep behaviours and thus were more susceptible to developing MetS. This result was consistent with previous studies. ${ }^{26,27}$ In other studies, both the severity and duration of obesity were positively associated with incident MetS, suggesting that MHO is a transient state in the pathway to MetS.

This study also demonstrated that BMI categories were associated with profiles of longitudinal changes in fasting plasma glucose, systolic blood pressure, and diastolic blood pressure in both males and females. Our findings were consistent with previous studies. For example, a prospective 4.5-year cohort study of individuals aged 40-65 years also found that BMI is the central feature of MetS in both sexes by analyzing BMI change and the contributions of BMI to MetS components. ${ }^{10}$ Inflammation could be an underlying factor that determines the differences in metabolic profiles between subgroups of obesity. ${ }^{28}$ An improved understanding and characterization of these subgroups should help in the development of innovative approaches to treat obesity effectively. Although it is unclear whether there is a unifying pathophysiological mechanism resulting in MetS, abdominal adiposity appears to be central to MetS and each of its individual components. ${ }^{29,30}$ These findings help to explain the association between subclinical inflammation and the risk of metabolic complications.

In our study, MHO or MHOW people had elevated blood pressure as a secondary MetS component. Another study confirmed that in both males and females, MHO people had higher blood pressure, and people with MetS tended to have hypertension. ${ }^{31-33}$ This is mainly a consequence of systemic low-grade inflammation. An important link between obesity and MetS seems to be the development of insulin resistance in peripheral tissues, leading to an enhanced hepatic flux of fatty acids from dietary sources, intravascular lipolysis, and adipose tissue resistance to the antilipolytic effects of insulin. ${ }^{34}$ Previous reports have indicated that a pro-inflammatory state and oxidative stress are crucial for evaluating cardiometabolic risk. Factors including acylation-stimulating protein, thyroid-stimulating hormone, creatinine, serum lipoprotein(a), platelet-activating factor acetyl hydrolase, and asymmetric dimethyl arginine are key factors in the triggering of systemic low-grade inflammation and enhancing autoimmune reactions, which may induce obesity and MetS. ${ }^{35}$ However, the components of MetS are reported to cluster in a way that varies between different populations. ${ }^{31,36,37}$ 


\begin{tabular}{|c|c|c|c|c|c|c|c|c|c|c|c|c|c|c|c|c|c|c|c|c|c|c|c|c|c|}
\hline & $\begin{array}{l}\stackrel{0}{\varrho} \\
\stackrel{2}{4}\end{array}$ & & & & & & $\tilde{N}$ & $\infty$ & 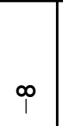 & & Ln & $m$ & - & & $\bar{N}$ & $\varphi$ & $\uparrow$ & & Lे & $\frac{0}{1}$ & $\uparrow$ & & $\underline{\infty}$ & $\uparrow$ & i \\
\hline 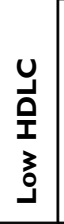 & 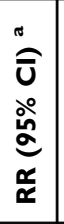 & $\stackrel{8}{-}$ & 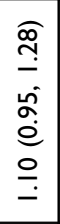 & 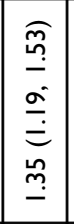 & 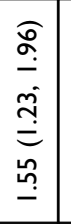 & $\stackrel{8}{-}$ & 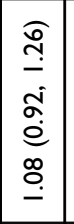 & 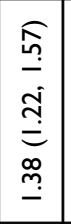 & 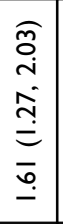 & $\stackrel{\circ}{-}$ & 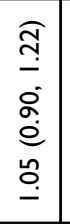 & 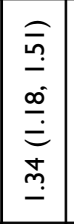 & 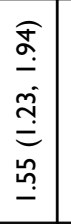 & $\underset{-}{8}$ & 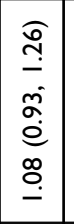 & 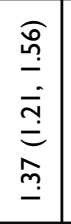 & 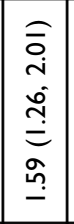 & $\stackrel{8}{-}$ & $\begin{array}{l}\widehat{\widehat{O}} \\
\stackrel{0}{0} \\
0 \\
\stackrel{0}{0} \\
\stackrel{0}{0} \\
\stackrel{-}{-}\end{array}$ & 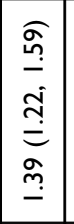 & 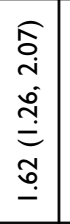 & 움 & 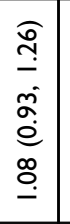 & 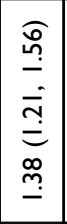 & 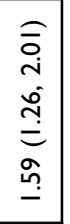 \\
\hline$\frac{n}{\tilde{d}}$ & $\begin{array}{l}\stackrel{0}{\varrho} \\
\stackrel{0}{2}\end{array}$ & & & & & & 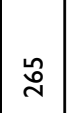 & $T$ & 으 & & $\stackrel{\text { fे }}{\text { for }}$ & $\frac{m}{1}$ & 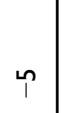 & & 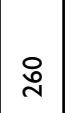 & 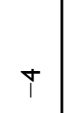 & $N$ & & $\underline{\hat{0}}$ & - & $\wedge$ & & กิ & $\tau$ & $m$ \\
\hline 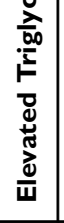 & 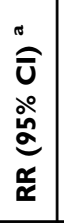 & $\stackrel{8}{-}$ & $\begin{array}{l}\widehat{\sigma} \\
\stackrel{m}{0} \\
\bar{o} \\
\stackrel{0}{0} \\
\overline{0} \\
\bar{o}\end{array}$ & 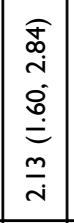 & 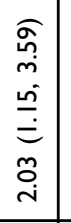 & $\stackrel{\circ}{\circ}$ & 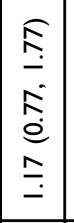 & 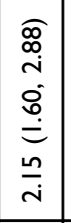 & 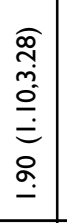 & $\stackrel{8}{-}$ & 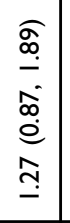 & 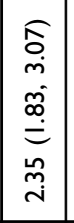 & 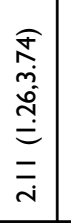 & $\stackrel{\circ}{-}$ & 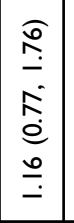 & 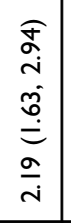 & 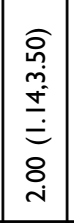 & $\stackrel{8}{-}$ & 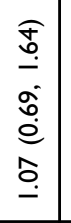 & 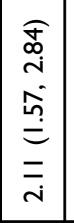 & 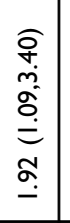 & $\stackrel{8}{-}$ & 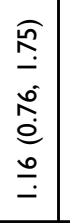 & 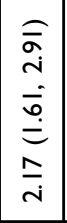 & 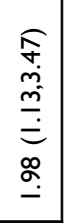 \\
\hline & $\begin{array}{l}\stackrel{\varrho}{\varrho} \\
\stackrel{\circ}{4}\end{array}$ & & & & & & $\bar{\sim}$ & $\approx$ & $\underline{\underline{n}}$ & & $\underline{\underline{n}}$ & $\stackrel{ \pm}{\sim}$ & $\simeq$ & & $\underline{a}$ & $\bar{N}$ & \pm & & $\infty$ & ㅇ & $\underline{\underline{n}}$ & & $\underline{a}$ & $\bar{\sim}$ & $\underline{\underline{n}}$ \\
\hline 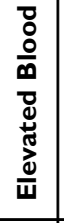 & 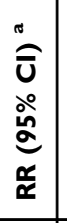 & $\stackrel{8}{-}$ & $\begin{array}{l}\widehat{f} \\
0 \\
0 \\
\hat{n} \\
0 \\
0 \\
\hat{n} \\
0\end{array}$ & 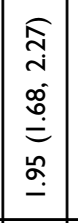 & 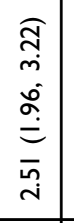 & $\stackrel{8}{\circ}$ & $\begin{array}{l}\widehat{\bar{o}} \\
\overline{-} \\
\dot{0} \\
\stackrel{0}{0} \\
\infty \\
\stackrel{0}{0}\end{array}$ & 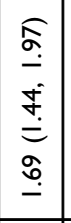 & 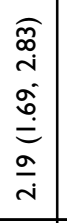 & $\stackrel{8}{-}$ & 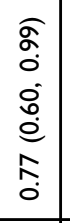 & 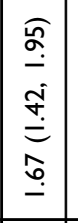 & 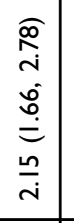 & $\stackrel{8}{-}$ & $\begin{array}{l}\widehat{\delta} \\
\stackrel{0}{0} \\
\dot{0} \\
\dot{0} \\
\infty \\
\stackrel{0}{0}\end{array}$ & 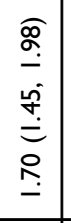 & 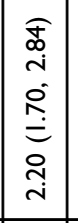 & $\stackrel{8}{-}$ & 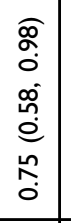 & 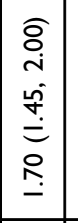 & 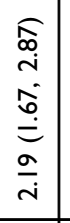 & $\stackrel{8}{-}$ & $\begin{array}{l}\widehat{o} \\
\stackrel{0}{0} \\
\dot{0} \\
\stackrel{0}{0} \\
\infty \\
\stackrel{0}{\circ}\end{array}$ & 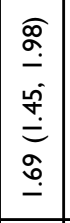 & 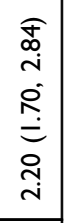 \\
\hline 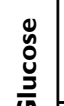 & $\begin{array}{l}\stackrel{\circ}{\circ} \\
\stackrel{2}{4}\end{array}$ & & & & & & $\frac{\sigma}{1}$ & $\stackrel{\circ}{m}$ & $\tilde{m}$ & & $\uparrow$ & q & $\stackrel{\infty}{m}$ & & $\frac{\infty}{1}$ & $\stackrel{\circ}{m}$ & $\stackrel{\sim}{m}$ & & - & 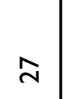 & 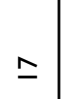 & & $\stackrel{i}{i}$ & $\hat{m}$ & శె \\
\hline 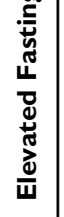 & 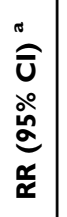 & $\stackrel{8}{-}$ & 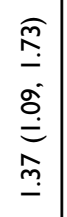 & 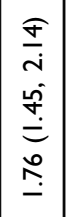 & 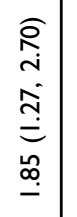 & $\stackrel{8}{-}$ & 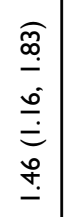 & 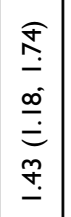 & 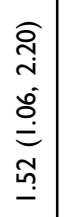 & $\stackrel{8}{-}$ & 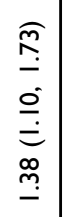 & 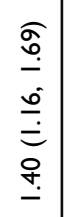 & 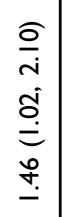 & $\underset{-}{\circ}$ & 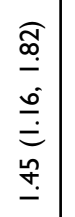 & 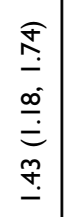 & 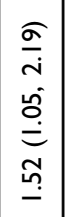 & $\underset{-}{8}$ & 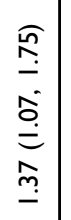 & 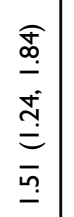 & 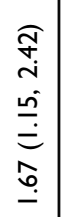 & $\underset{-1}{8}$ & 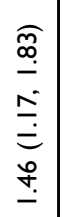 & 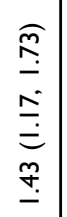 & 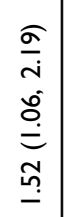 \\
\hline 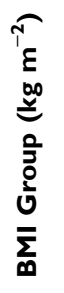 & & 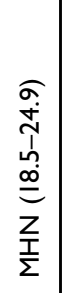 & 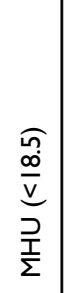 & 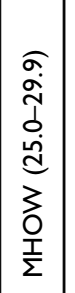 & 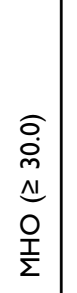 & 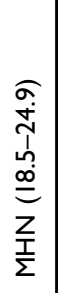 & 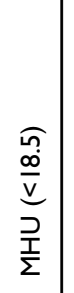 & 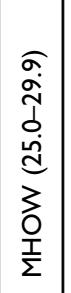 & 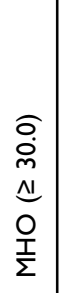 & 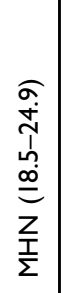 & 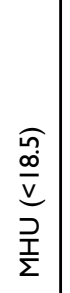 & 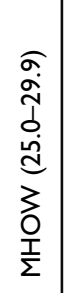 & 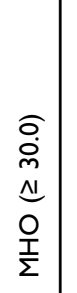 & 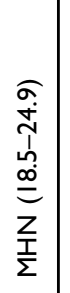 & 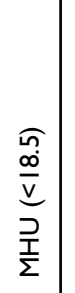 & 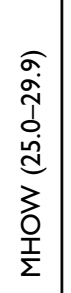 & 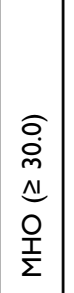 & 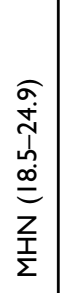 & $\begin{array}{l}\frac{1}{0} \\
\frac{\infty}{v} \\
\stackrel{v}{\Sigma} \\
\frac{T}{\Sigma}\end{array}$ & 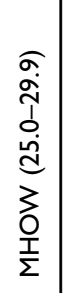 & 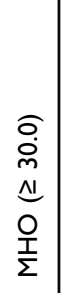 & 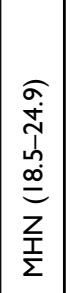 & $\begin{array}{l}\frac{\Omega}{0} \\
\frac{0}{v} \\
v \\
\stackrel{T}{\Sigma} \\
\frac{T}{\Sigma}\end{array}$ & 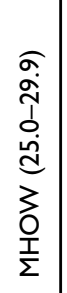 & 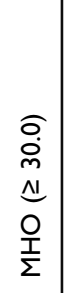 \\
\hline & & $\begin{array}{l}\frac{*}{\mathrm{v}} \\
\mathrm{o} \\
\mathrm{g} \\
\overline{\bar{z}} \\
\mathrm{z}\end{array}$ & & & & 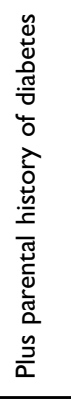 & & & & 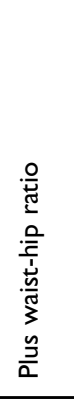 & & & & 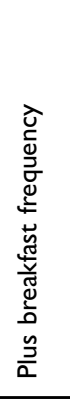 & & & & 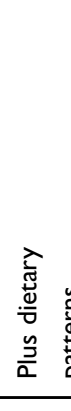 & & & & 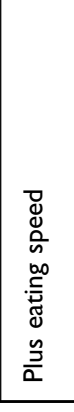 & & & \\
\hline
\end{tabular}




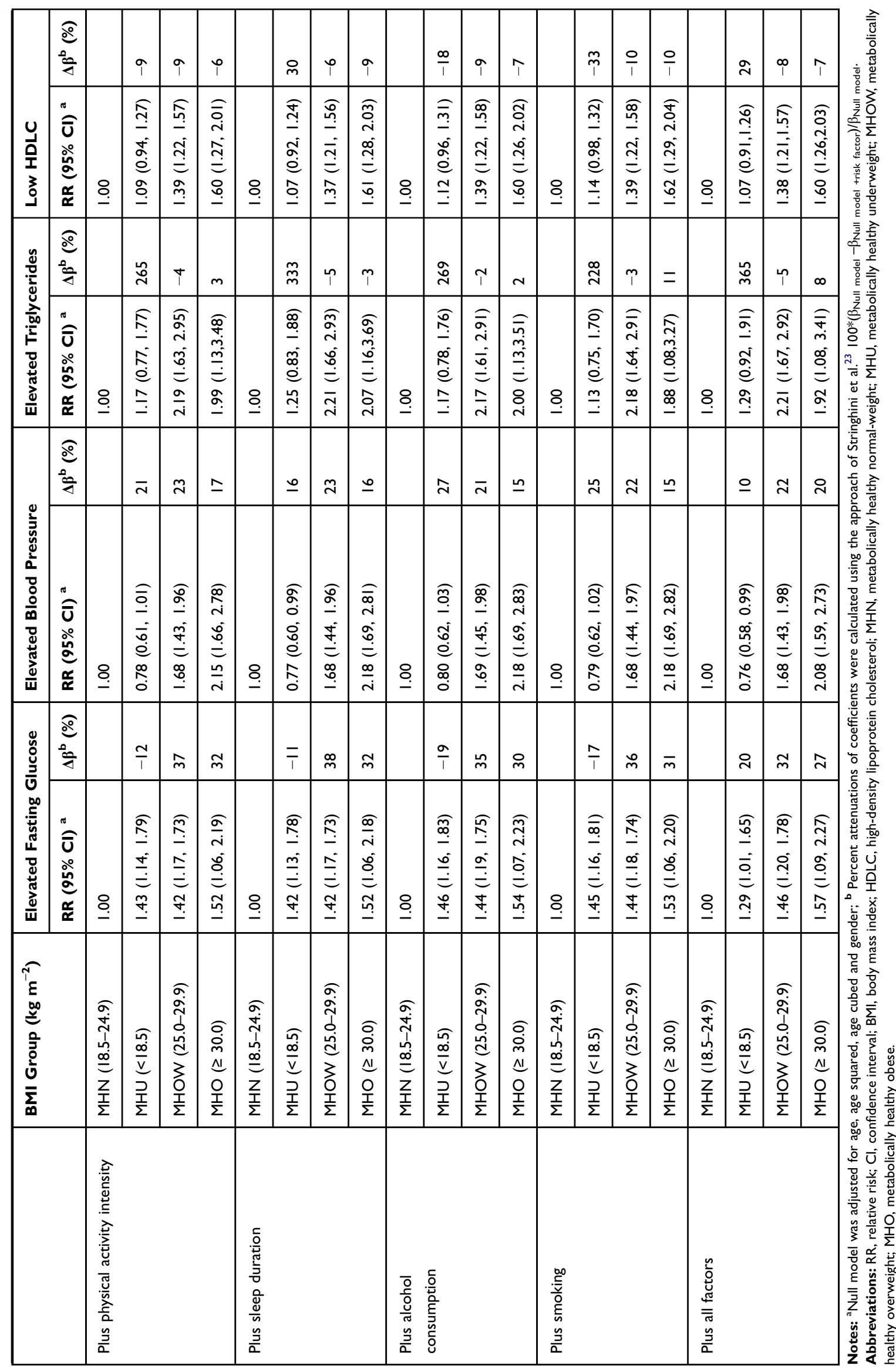


Table 4 Top Ten Transitions of Metabolic Status from Baseline BMI Categories to Status at Follow-Up

\begin{tabular}{|c|c|c|c|c|c|c|c|}
\hline & $\begin{array}{l}\text { Rules } \\
\text { No. }\end{array}$ & $\begin{array}{l}\text { BMI Categories at } \\
\text { baseline }\end{array}$ & $\begin{array}{l}\text { Metabolic Status at } \\
\text { follow-up }\end{array}$ & $\mathbf{n}$ & $\begin{array}{l}\text { Confidence } \\
\text { Rate (\%) }\end{array}$ & $\begin{array}{l}\text { Support Rate } \\
\text { (\%) }\end{array}$ & $\begin{array}{l}\text { Lift } \\
\text { value }\end{array}$ \\
\hline \multirow[t]{10}{*}{ Total } & I & $\mathrm{MHU}$ & Absence & 1898 & 72.7 & 17.5 & I.I \\
\hline & 2 & $\mathrm{MHN}$ & Absence & 4313 & 72.4 & 39.7 & I.I \\
\hline & 3 & $\mathrm{MHO}$ & Obese & 39 & 22.5 & 0.4 & 28.8 \\
\hline & 4 & $\mathrm{MHO}$ & Obese \&HBP & 33 & 19.1 & 0.3 & 31.9 \\
\hline & 5 & MHOW & HBP & 342 & 16.6 & 3.2 & 1.7 \\
\hline & 6 & MHOW & HTG & 191 & 9.3 & 1.8 & 1.4 \\
\hline & 7 & MHU & HFPG & 236 & 9.0 & 2.2 & 1.2 \\
\hline & 8 & MHOW & HFPG \&HBP & 77 & 3.7 & 0.7 & 1.8 \\
\hline & 9 & MHOW & HBP \&HTG & 64 & 3.1 & 0.6 & 1.7 \\
\hline & 10 & MHOW & HFPG \&HTG & 42 & 2.0 & 0.4 & 1.4 \\
\hline \multirow[t]{10}{*}{ Men } & 1 & $\mathrm{MHN}$ & Absence & 1986 & 63.6 & 36.6 & I.I \\
\hline & 2 & MHU & Absence & 324 & 58.6 & 6.0 & 1.0 \\
\hline & 3 & $\mathrm{MHO}$ & Obese & 31 & 22.0 & 0.6 & 20.6 \\
\hline & 4 & $\mathrm{MHO}$ & Obese \&HBP & 29 & 20.6 & 0.5 & 21.5 \\
\hline & 5 & MHOW & HBP & 261 & 16.6 & 4.8 & 1.3 \\
\hline & 6 & MHU & HFPG & 65 & 11.8 & 1.2 & 1.4 \\
\hline & 7 & MHOW & HTG & 153 & 9.7 & 2.8 & I.I \\
\hline & 8 & $\mathrm{MHO}$ & Obese \&HFPG \&HBP & 8 & 5.7 & 0.2 & 15.4 \\
\hline & 9 & $\mathrm{MHO}$ & Obese \&HTG & 8 & 5.7 & 0.2 & 12.8 \\
\hline & 10 & $\mathrm{MHO}$ & Obese \&HBP \&HTG & 7 & 5.0 & 0.1 & 13.5 \\
\hline \multirow[t]{10}{*}{ Women } & I & MHN & Absence & 2327 & 82.2 & 42.8 & I.I \\
\hline & 2 & $\mathrm{MHO}$ & Obese & 8 & 25.0 & 0.2 & 50.3 \\
\hline & 3 & MHOW & HBP & 81 & 16.5 & 1.5 & 2.3 \\
\hline & 4 & MHU & HFPG & 171 & 8.3 & 3.2 & 1.3 \\
\hline & 5 & MHOW & HTG & 38 & 7.8 & 0.7 & 1.7 \\
\hline & 6 & MHU & HTG & 100 & 4.9 & 1.8 & 1.0 \\
\hline & 7 & MHOW & HFPG\&HBP & 11 & 2.2 & 0.2 & 2.3 \\
\hline & 8 & MHOW & Obese & 8 & 1.6 & 0.2 & 3.3 \\
\hline & 9 & MHU & HFPG\&HBP & 26 & 1.3 & 0.5 & 1.3 \\
\hline & 10 & MHOW & Obese \&HBP \&HTG & 6 & 1.2 & 0.1 & 6.7 \\
\hline
\end{tabular}

Abbreviations: $\mathrm{BMI}$, body mass index; MHU, metabolically healthy underweight; MHN, metabolically healthy normal-weight; MHO, metabolically healthy obese; MHOW, metabolically healthy overweight; HBP, high blood pressure; HTG, high triglyceride; HFPG, high fasting plasma glucose.

We also found that MHU people had impaired fasting glucose. The potential inverse relationship between vitamin $\mathrm{D}$ status and MetS may be attributable to the conjunctive effects of obesity and incident insulin resistance. ${ }^{38}$ Most subjects who started off as healthy remained healthy in the study, which is similar to the result 


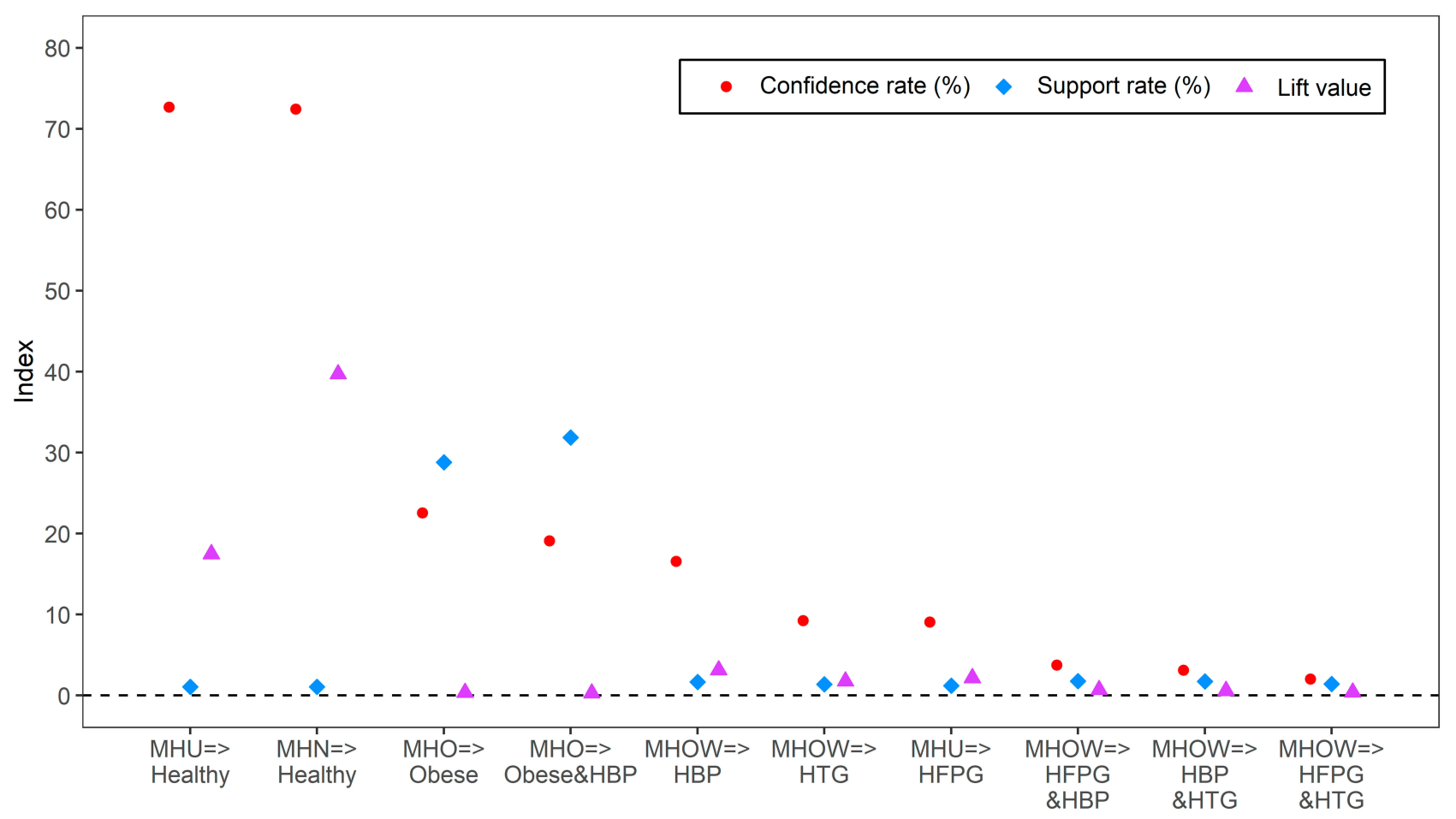

Figure 2 Top ten transitions of metabolic status from baseline BMI categories to status at follow-up in all subjects.

Abbreviations: $\mathrm{MHU}$, metabolically healthy underweight; Healthy, with absence of any MetS components; MHN, metabolically healthy normal-weight; MHO, metabolically healthy obese; MHOW, metabolically healthy overweight; HBP, high blood pressure; HTG, high triglyceride; HFPG, high fasting plasma glucose.

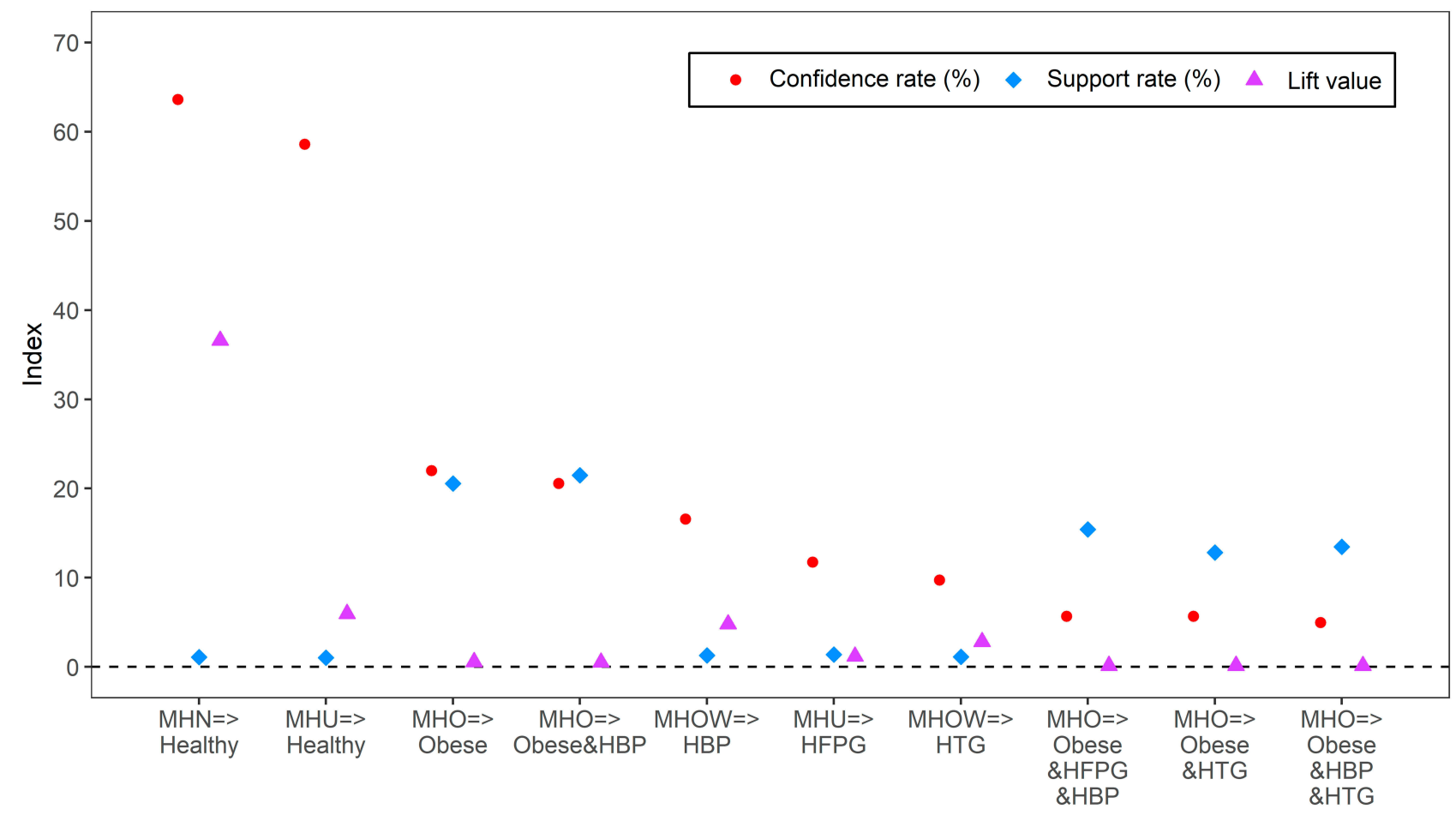

Figure 3 Top ten transitions of metabolic status from baseline BMl categories to status at follow-up in men.

Abbreviations: $\mathrm{MHN}$, metabolically healthy normal-weight; Healthy, with absence of any MetS components; MHU, metabolically healthy underweight; MHO, metabolically healthy obese; HBP, high blood pressure; MHOW, metabolically healthy overweight; HFPG, high fasting plasma glucose; HTG, high triglyceride. 


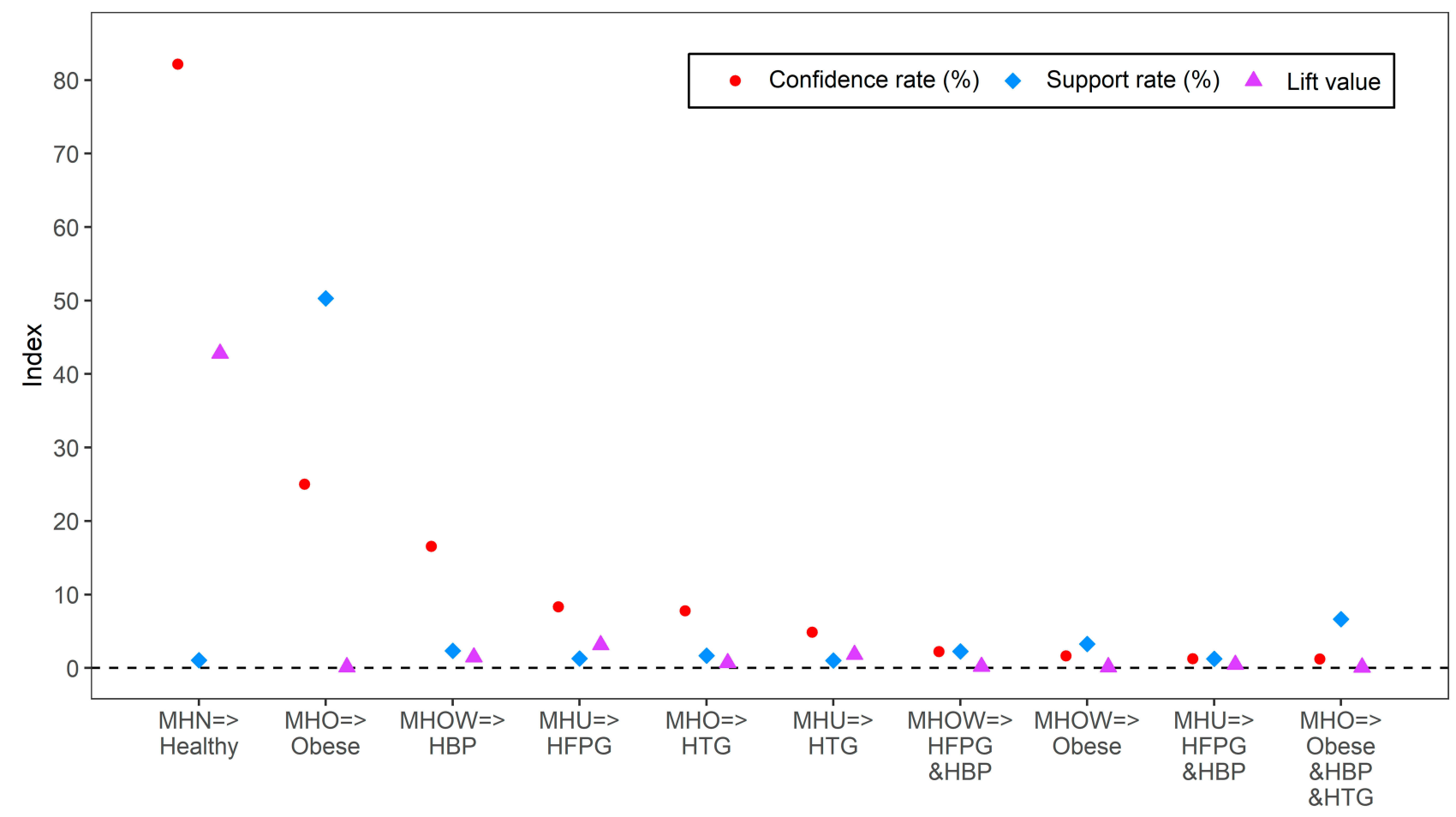

Figure 4 Top ten transitions of metabolic status from baseline BMI categories to status at follow-up in women.

Abbreviations: MHN, metabolically healthy normal-weight; Healthy, with absence of any MetS components; MHO, metabolically healthy obese; MHOW, metabolically healthy overweight; HBP, high blood pressure; MHU, metabolically healthy underweight; HFPG, high fasting plasma glucose; HTG, high triglyceride.

of a previous study in a German population. ${ }^{39}$ In most circumstances, "healthy" was the predominant status in our study, and subjects with a single MetS component tended to return to a "healthy" status. However, MHO was shown to be a transient state in Japanese Americans, with nearly two-thirds developing metabolically unhealthy obesity over 10 years, with a higher conversion to metabolically unhealthy obesity independently associated with visceral and abdominal adiposity, higher fasting insulin level and lower baseline high-density lipoprotein cholesterol levels. ${ }^{40}$

In addition to the five components of MetS, the prothrombotic and pro-inflammatory states are essential features based on the evidence of impaired function of adipose tissue. This seems to be an important mechanism determining the individual risk of developing metabolic and cardiovascular comorbidities. ${ }^{41-43}$ Additionally, an important study provided evidence for the development of adipose tissue dysfunction in which adipokine secretion was significantly altered towards a pro-inflammatory, atherogenic and diabetogenic pattern. ${ }^{41}$ These changes in adipokine secretion presumably link impaired adipose tissue function to insulin resistance and cardiovascular disease. ${ }^{42}$ Several studies have shown that a steep increase in BMI towards overweight and obesity is the major cause of the growing prevalence of diabetes and vice versa. ${ }^{44}$

Obesity has been found to be independently and significantly related to diabetes, cardiovascular mortality and coronary artery disease risk. ${ }^{45,46}$ To prevent increasing morbidity and mortality due to obesity-related diabetes, MetS and cardiovascular disease, there is an urgent need to initiate large-scale community intervention programmes focusing on increased efforts in the context of lifestyle and dietary behaviours. Recent studies have focused on sleep behaviours, sedentary behaviours and low physical activity levels. $^{47}$ These behaviours are highly complex, operating in synergy with each other, disrupting the link between regulation of the circadian clock and metabolic physiology and impacting various components of daily energy expenditure and feeding behaviours to promote obesity. As such, the behavioural triad (nutrition, movement and sleep) presents plenty of opportunities for intervention and optimization in the context of body weight regulation and MetS prevention. Another study showed differences in weight change between MHN and MHO adults, which supports recommendations for weight loss in $\mathrm{MHO}$ individuals to avoid increasing risk factors associated with weight maintenance and weight gain. ${ }^{48}$ 


\section{Strengths and Limitations}

Our study has several strengths. This study is the first to evaluate the influence of metabolically healthy obesity on the longitudinal path to MetS and its components in Chinese urban adults after adjusting for dietary habits, lifestyles factors and sleep behaviours. The second strength is that the study collected data from a relatively large population. Finally, the prospective cohort study design and relatively long follow-up period help determine the true relationship between BMI categories and MetS among metabolically healthy adults. However, several limitations need to be addressed. First, this study was conducted using a sample of the Beijing population, and therefore our findings have limited generalizability to other populations. Second, because information regarding lifestyle was self-reported, measurement errors are inevitable. Third, several transitions occurred in a limited number of participants, which may be a limitation to assessing the health status transition.

\section{Conclusion}

MHO and MHOW statuses were associated with the incidence of metabolic abnormalities. MHO and MHOW participants developed elevated blood pressure most frequently, and MHU subjects developed elevated blood glucose most commonly regardless of sex. More effective risk mitigation strategies are needed for MHO people to prevent them from developing MetS.

\section{Abbreviation}

BMI, body mass index; MHO, metabolically healthy obese; MHOW, metabolically healthy overweight; MHN, metabolically healthy normal-weight; MHU, metabolically healthy underweight; MetS, metabolic syndrome; FPG, fasting plasma glucose; HDLC, high-density lipoprotein cholesterol; RR, relative risk; CI, confidence interval; ARM, association rule mining; SD, standard deviation; TG, triglyceride; SBP, systolic blood pressure; DBP, diastolic blood pressure; HBP, high blood pressure; HTG, high triglyceride; HFPG, high fasting plasma glucose.

\section{Data Sharing Statement}

The data that support the findings of this study are available from the Beijing Health Management Cohort (BHMC) study, but restrictions apply to the availability of these data, which were used under license for the current study and so are not publicly available. Data are however available from the corresponding author upon reasonable request and with permission of the Capital Medical University.

\section{Acknowledgments}

This study was supported by National Natural Science Foundation of China (serial numbers 81530087, 81502886 and 81373099), Beijing Municipal Natural Science Foundation (serial numbers Z160002, 7131002), Beijing Municipal Training Project of Excellent Talents, and Nature Science Foundation of Capital Medical University (serial number PYZ2018046). The funding was neither used for the study design nor data collection but to cover for the publication fees. We thank Zhiwei Li for his substantial contributions in the revision of manuscript.

\section{Author Contributions}

All authors participated in the study design and data collection. All authors contributed to data analysis, drafting or revising the article, gave final approval of the version to be published and agree to be accountable for all aspects of the work.

\section{Disclosure}

The authors report no conflicts of interest in this work.

\section{References}

1. Piccolo R, Giustino G, Mehran R, et al. Stable coronary artery disease: revascularisation and invasive strategies. Lancet. 2015;386 (9994):702-713. doi:10.1016/S0140-6736(15)61220-X

2. Benjamin EJ, Muntner P, Alonso A, et al. Heart disease and stroke statistics-2019 update: a report from the American Heart Association. Circulation. 2019;139:e56-e528. doi:10.1161/CIR.0000000000000659

3. Hu SS, Gao RL, Liu LS, et al. Summary of the 2018 report on cardiovascular diseases in China. Chin Circ J. 2019;34:209-220.

4. Williams $\mathrm{KJ}, \mathrm{Wu} \mathrm{X}$. Imbalanced insulin action in chronic over nutrition: clinical harm, molecular mechanisms, and a way forward. Atherosclerosis. 2016;247:225-282. doi:10.1016/j.atherosclerosis.2016.02.004

5. Gurka MJ, Filipp SL, Musani SK, et al. Use of BMI as the marker of adiposity in a metabolic syndrome severity score: derivation and validation in predicting long-term disease outcomes. Metabolism. 2018;83:68-74. doi:10.1016/j.metabol.2018.01.015

6. Saklayen MG. The global epidemic of the metabolic syndrome. Curr Hypertens Rep. 2018;20(2):12. doi:10.1007/s11906-018-0812-z

7. Lu JL, Wang LM, Li M, et al. Metabolic syndrome among adults in China: the 2010 China noncommunicable disease surveillance. J Clin Endocrinol Metab. 2017;102(2):507-515. doi:10.1210/jc.2016-2477

8. Cameron AJ, Boyko EJ, Sicree RA, et al. Central obesity as a precursor to the metabolic syndrome in the AusDiab study and Mauritius. Obesity. 2008;16(12):2707-2716. doi:10.1038/oby.2008.412

9. Weber KE, Fischl AF, Murray PJ, et al. Effect of BMI on cardiovascular and metabolic syndrome risk factors in an Appalachian pediatric population. Diabetes Metab Syndr Obes. 2014;7:445-453. doi: $10.2147 / \mathrm{dmso.S68283}$ 
10. Maison P, Byrne CD, Hales CN, et al. Do different dimensions of the metabolic syndrome change together over time? Evidence supporting obesity as the central feature. Diabetes Care. 2001;24(10):1758 1763. doi:10.2337/diacare.24.10.1758

11. Pienkowska J, Brzeska B, Kaszubowski M, et al. MRI assessment of ectopic fat accumulation in pancreas, liver and skeletal muscle in patients with obesity, overweight and normal BMI in correlation with the presence of central obesity and metabolic syndrome. Diabetes Metab Syndr Obes. 2019;12:623-636. doi:10.2147/dmso.S194690

12. Hillier TA, Fagot-Campagna A, Eschwège E, et al. Weight change and changes in the metabolic syndrome as the French population moves towards overweight: the D.E.S.I.R. cohort. Int J Epidemiol. 2006;35(1):190-196. doi:10.1093/ije/dyi281

13. Chuang SY, Chou P, Hsu PF, et al. Presence and progression of abdominal obesity are predictors of future high blood pressure and hypertension. Am J Hypertens. 2006;19(8):788-795. doi:10.1016/j. amjhyper.2006.01.010

14. Bradshaw PT, Reynolds KR, Wagenknecht LE, et al. Incidence of components of metabolic syndrome in the metabolically healthy obese over 9 years follow-up: the Atherosclerosis Risk In Communities study. Int $J$ Obes (Lond). 2018;42(3):295-301. doi:10.1038/ijo.2017.249

15. Liu J, Tao LX, Zhao Z, et al. 2-year changes in hyperuricemia and risk of diabetes: a 5-year Prospective Cohort Study. J Diabetes Res. 2018;2018:6905720. doi:10.1155/2018/6905720

16. Liu XT, Li ZW, Zhang JB, et al. A novel risk score for type 2 diabetes containing sleep duration: a 7-year prospective cohort study among Chinese participants. $J$ Diabetes Res. 2020;2020:2969105. doi:10.1155/2020/2969105

17. Zhang L, Cordeiro LS, Liu J, et al. The association between breakfast skipping and body weight, nutrient intake, and metabolic measures among participants with metabolic syndrome. Nutrients. 2017;9 (4):384. doi:10.3390/nu9040384

18. Saito M, Shimazaki Y, Nonoyama T, et al. Number of teeth, oral selfcare, eating speed, and metabolic syndrome in an aged Japanese population. J Epidemiol. 2019;29(1):26-32. doi:10.2188/jea.JE20170210

19. Alberti KG, Eckel RH, Grundy SM, et al. Harmonizing the metabolic syndrome: a joint interim statement of the international diabetes federation task force on epidemiology and prevention; National Heart, Lung, and Blood Institute; American Heart Association; World Heart Federation; International Atherosclerosis Society; and International Association for the Study of Obesity. Circulation. 2009;120(16):1640-1645. doi:10.1159/000365591

20. Hu H, Kurotani K, Sasaki N, et al. Optimal waist circumference cutoff points and ability of different metabolic syndrome criteria for predicting diabetes in Japanese men and women: japan epidemiology collaboration on occupational health study. BMC Public Health. 2016;16(1):220. doi:10.1186/s12889-016-2856-9

21. WHO Expert Consultation. Appropriate body-mass index for Asian populations and its implications for policy and intervention strategies. Lancet. 2004;363(9403):157-163. doi:10.1016/S0140-6736(03)15268-3.

22. Yelland LN, Salter AB, Ryan P. Performance of the modified poisson regression approach for estimating relative risks from clustered prospective data. Am J Epidemiol. 2011;174(8):984. doi:10.1093/aje/ kwr183

23. Stringhini S, Dugravot A, Shipley M, et al. Health behaviours, socioeconomic status, and mortality: further analyses of the British Whitehall II and the French GAZEL prospective cohorts. PLoS Med. 2011;8(2):e1000419. doi:10.1371/journal.pmed.1000419

24. Park SH, Jang SY, Kim H, et al. An association rule mining-based framework for understanding lifestyle risk behaviors. PLoS One. 2014;9(2):e88859. doi:10.1371/journal.pone.0088859

25. Lee DG, Ryu KS, Bashir M, et al. Discovering medical knowledge using association rule mining in young adults with acute myocardial infarction. J Med Syst. 2013;37(2):9896. doi:10.1007/s10916-0129896-1
26. Mongraw-Chaffin M, Foster MC, Kalyani RR, et al. Obesity severity and duration are associated with incident metabolic syndrome: evidence against metabolically healthy obesity from the multi-ethnic study of atherosclerosis. J Clin Endocrinol Metab. 2016;101 (11):4117-4124. doi:10.1210/jc.2016-2460

27. Kanagasabai T, Thakkar NA, Kuk JL, et al. Differences in physical activity domains, guideline adherence, and weight history between metabolically healthy and metabolically abnormal obese adults: a cross-sectional study. Int J Behav Nutr Phys Act. 2015;12(1):64. doi:10.1186/s12966-015-0227-z

28. Karelis AD, Rabasa-Lhoret R. Obesity: can inflammatory status define metabolic health? Nat Rev Endocrinol. 2013;9(12):694-695. doi:10.1038/nrendo.2013.198

29. Franco OH, Massaro JM, Civil J, et al. Trajectories of entering the metabolic syndrome: the Framingham heart study. Circulation. 2009;120(20):1943-1950. doi:10.1161/CIRCULATIONAHA.109. 855817

30. Al-Bachir M, Bakir MA. Predictive value of body mass index to metabolic syndrome risk factors in Syrian adolescents. $J$ Med Case Rep. 2017;11(1):170. doi:10.1186/s13256-017-1315-2

31. Huo D, Tao L, Li X, et al. Association of blood pressure with development of metabolic syndrome components: a five-year Retrospective Cohort study in Beijing. BMC Public Health. 2013;13(1):912. doi:10.1186/1471-2458-13-912

32. Yadav D, Mishra M, Tiwari A, et al. Prevalence of dyslipidemia and hypertension in Indian type 2 diabetic patients with metabolic syndrome and its clinical significance. Osong Public Health Res Perspect. 2014;5(3):169-175. doi:10.1016/j.phrp.2014.04.009

33. Knowles KM, Paiva LL, Sanchez SE, et al. Waist circumference, body mass index, and other measures of adiposity in predicting cardiovascular disease risk factors among Peruvian adults. Int $J$ Hypertens. 2011;2011:931402. doi:10.4061/2011/931402

34. Klop B, Elte JW, Cabezas MC. Dyslipidemia in obesity: mechanisms and potential targets. Nutrients. 2013;5(4):1218-1240. doi:10.3390/ nu5041218

35. Onat A, Can G. Enhanced proinflammatory state and autoimmune activation: a breakthrough to understanding chronic diseases. Curr Pharm Des. 2014;20(4):575-584. doi:10.2174/13816128200414021 3145551

36. Tao LX, Wang W, Zhu HP, et al. Risk profiles for metabolic syndrome and its transition patterns for the elderly in Beijing, 1992-2009. Endocrine. 2014;47:161-168. doi:10.1007/s12020-0130143-4

37. Liu X, Tao L, Cao K, et al. Association of high-density lipoprotein with development of metabolic syndrome components: a five-year follow-up in adults. BMC Public Health. 2015;15(1):412. doi:10.1186/s12889-015-1747-9

38. Huang CY, Chang HH, Lu CW, et al. Vitamin D status and risk of metabolic syndrome among non-diabetic young adults. Clin Nutr. 2015;34(3):484-489. doi:10.1016/j.clnu.2014.05.010

39. Haring R, Rosvall M, Völker U, et al. A network-based approach to visualize prevalence and progression of metabolic syndrome components. PLoS One. 2012;7(6):e39461. doi:10.1371/journal.pone.00 39461

40. Hwang YC, Hayashi T, Fujimoto WY, et al. Visceral abdominal fat accumulation predicts the conversion of metabolically healthy obese subjects to an unhealthy phenotype. Int J Obes. 2015;39(9):13651370. doi:10.1038/ijo.2015.75

41. Van Gaal LF, Mertens IL, De Block CE. Mechanisms linking obesity with cardiovascular disease. Nature. 2006;444(7121):875-880. doi:10.1038/nature05487

42. Bays HE. Adiposopathy, diabetes mellitus, and primary prevention of atherosclerotic coronary artery disease: treating "sick fat" through improving fat function with antidiabetes therapies. Am J Cardiol. 2012;110(9 Suppl):4b-12b. doi:10.1038/nature05487 
43. Bays HE. Adiposopathy is "sick fat" a cardiovascular disease? $J \mathrm{Am}$ Coll Cardiol. 2011;57(25):2461-2473. doi:10.1016/j.jacc.2011.02.038

44. Pedersen SD. Metabolic complications of obesity. Best Pract Res $\mathrm{Cl}$ En. 2013;27(2):179-193. doi:10.1016/j.beem.2013.02.004

45. Bodegard J, Sundström J, Svennblad B, et al. Changes in body mass index following newly diagnosed type 2 diabetes and risk of cardiovascular mortality: a cohort study of 8486 primary-care patients. Diabetes Metab. 2013;39(4):306-313. doi:10.1016/j.diabet.2013.05.004

46. Ferguson TF, Funkhouser E, Roseman J. Factor analysis of metabolic syndrome components in the Coronary Artery Risk Development in Young Adults (CARDIA) study: examination of factors by race-sex groups and across time. Ann Epidemiol. 2010;20:194-200. doi:10.1016/ j.annepidem.2009.11.002
47. Dulloo AG, Miles-Chan JL, Montani JP. Nutrition, movement and sleep behaviours: their interactions in pathways to obesity and cardiometabolic diseases. Obes Rev. 2017;18(Suppl 1):3-6. doi:10.1111/ obr.12513

48. Cui Z, Truesdale KP, Bradshaw PT, et al. Three-year weight change and cardiometabolic risk factors in obese and normal weight adults who are metabolically healthy: the atherosclerosis risk in communities study. Int $J$ Obes. 2015;39(8):1203-1208. doi:10.1038/ ijo.2015.56

\section{Publish your work in this journal}

Diabetes, Metabolic Syndrome and Obesity: Targets and Therapy is an international, peer-reviewed open-access journal committed to the rapid publication of the latest laboratory and clinical findings in the fields of diabetes, metabolic syndrome and obesity research. Original research, review, case reports, hypothesis formation, expert opinion and commentaries are all considered for publication. The manuscript management system is completely online and includes a very quick and fair peer-review system, which is all easy to use. Visit http://www.dovepress.com/testimonials.php to read real quotes from published authors.

Submit your manuscript here: https:/www.dovepress.com/diabetes-metabolic-syndrome-and-obesity-targets-and-therapy-journal 